\title{
The Method to Obtain the Rise and Fall of Anxiety, Estrogen, Progesterone and EEG Signals and Their Coincident Frequencies
}

\author{
Silvia Solís-Ortiz ${ }^{*}$, Rafael G. Campos² ${ }^{2}$ César Damián ${ }^{3}$ \\ ${ }^{1}$ Departamento de Ciencias Médicas, División de Ciencias de la Salud, Campus León, Universidad de Guanajuato, \\ León, México \\ ${ }^{2}$ Departamento de Ciencias, División de Ciencias e Ingenierías, Universidad de Quintana Roo, Chetumal, México \\ ${ }^{3}$ Departamento de Ingeniería Mecánica, División de Ingenierías, Campus Irapuato-Salamanca, Universidad de Guanajuato, \\ Salamanca, México \\ Email: ^silviasolis17@gmail.com, rafael.gonzalez@uqroo.edu.mx, cesar.damian@ugto.mx
}

How to cite this paper: Solís-Ortiz, S. Campos, R. G., \& Damián, C. (2019). The Method to Obtain the Rise and Fall of Anxiety, Estrogen, Progesterone and EEG Signals and Their Coincident Frequencies. Psychology, 10, 1043-1064.

https://doi.org/10.4236/psych.2019.107068

Received: April 15, 2019

Accepted: June 23, 2019

Published: June 26, 2019

Copyright (c) 2019 by author(s) and Scientific Research Publishing Inc.

This work is licensed under the Creative

Commons Attribution International

License (CC BY 4.0).

http://creativecommons.org/licenses/by/4.0/

\section{Open Access}

\begin{abstract}
Anxiety is a frequent mood disorder that occurs in females during the menstrual cycle. Little is known on a relation among anxiety, sex hormones and electroencephalographic signals in females. Although a relation between anxiety and EEG signals has been suggested, it is not known when anxiety starts to rise and when it falls and which is its relation with the rise and fall of the EEG and sex hormone signals. This investigation proposes a procedure to calculate the rise and fall of their signals and their frequencies using a short-time Fourier transform for a long-time period on anteriorly described dataset of absolute power of brain signals delta, theta, alpha1, alpha2, beta1 and beta2, estrogen, progesterone and anxiety scores along 28 days of the menstrual cycle. The comparison of each brain signal with sex hormones and anxiety signals, revealed that anxiety frequency 3 (every ten days), rose on day 8 and fell on day 18, a pattern which coincided with estrogen, progesterone and alpha1 frequencies. The estrogens rose on day 1 and fell on day 13, which coincided with delta, alpha1 and alpha2 frequencies, while the progesterone rose on day 11 and fell on day 25, which coincided with theta, alpha2, beta1 and beta2 frequencies, extending until the end of the menstrual cycle. When the anxiety frequency began its fall, the frequencies of alpha2, beta1 and beta2 began to rise between days 15 and 21 . The proposed method allowed understanding that the anxiety associated with the menstrual cycle coincides with the rise and fall of frequencies of sex hormones and EEG signals. This procedure can be applied to analyze severe anxiety disorders and conduct to the provision of the appropriate treatment.
\end{abstract}




\section{Keywords}

Anxiety, Estrogen, Progesterone, EEG, Short-Time Fourier Transform

\section{Introduction}

Numerous studies have reported changes in mood and affective disorders, including aggression, hostility, depression, irritability and anxiety, mainly during the luteal phase of the menstrual cycle (Bäckström et al., 2003; Gonda et al., 2008; Reed, Levin, \& Evans, 2008; Romans, Clarkson, Einstein, Petrovic, \& Stewart, 2012). It is estimated that menstrual symptoms are highly prevalent in $73 \%$ of women between 15 and 45 years of age and that these symptoms can have a significant impact on daily living, cognition and interpersonal relationships (Dueñas et al., 2011; Dennerstein, Lehert, \& Heinemann, 2012; Hantsoo \& Epperson, 2015). Furthermore, there is evidence that some women during the luteal phase of the cycle show an increase in the perception of stressful events (Woods et al., 1998; Ossewaarde et al., 2010) and in overall stress levels (Girdler, Straneva, Light, Pedersen, \& Morrow, 2001; Ossewaarde et al., 2013), which are likely due to hormonal influence (van Wingen et al., 2008).

It has been suggested that the increase in anxiety may be related to fluctuations in sex hormones during the menstrual cycle (Le Mellédo \& Baker, 2004; Sigmon, Whitcomb-Smith, Rohan, \& Kendrew, 2004; Nillni, Toufexis, \& Rohan, 2011). Many hypotheses about the etiology have been proposed, including the action of estrogens (ter Horst, 2010; Pfaff et al., 2000; Katzenellenbogen et al., 2000), increased levels of estradiol and progesterone (Redei \& Freeman, 1995; Ford, Lethaby, Roberts, \& Mol, 2012), and an increase in allopregnanolone during the luteal phase (Bäckström et al., 2014). However, some studies have not found abnormalities in the release of gonadotropins, gonadal steroids or androgens in women suffering from premenstrual symptoms (Schmidt, Purdy, Moore, Jr. Paul, \& Rubinow, 1994; Blum et al., 2004). For this reason, the implementation of new analytical tools seems to be required in the search to clarify the relationship between the action of hormones during the menstrual cycle and anxiety, usually through the analysis of electroencephalographic activity (EEG). EEG is a recording of the rhythmical electrical activity of the brain that is thought to derive from extracellular current flow associated with summated postsynaptic potentials in synchronously activated, pyramidal cells that are perpendicular to the cortical surface (Holmes \& Khazipov, 2007; Lopes da Silva, 2010; Jackson \& Bolger, 2014).

EEG measures the electrical cortical activity in the brain, with high temporal resolution, it provides a direct measure of the present functional state of the brain and of its different levels of arousal (Buzsáki, 2006). Resting EEG contains abundant information predictive of performance on several cognitive tasks (Basar \& Güntekin, 2008; Solís-Ortiz, Guevara, \& Corsi-Cabrera, 2004). Moreover, 
the EEG technique enables the analyze of the effects of sex hormones during the menstrual cycle (Solís-Ortiz, Ramos, Arce, Guevara, \& Corsi-Cabrera, 1994) and anxiety level (Solís-Ortiz \& Corsi-Cabrera, 2002).

Human EEG signals at rest oscillate in women depending on the phases of the menstrual cycle. For instance, EEG power is higher during the luteal phase and lower during the premenstrual and menstrual phases (Solís-Ortiz, Ramos, Arce, Guevara, \& Corsi-Cabrera, 1994; Becker, Creutzfeldt, Schwibbe, \& Wuttke, 1982; Vasil'eva, 2005), while the degree of coupling between the hemispheres takes longer in the luteal phase of the cycle (Hausmann, Hamm, Waldie, \& Kirk, 2013). Furthermore, progesterone influences the interhemispheric decoupling in the luteal phase of the cycle (Hausmann \& Güntürkün, 2008), and estradiol reduces brain asymmetry in the follicular phase of the cycle (Weis et al., 2008).

Some studies have suggested that EEG activity at rest is related with anxiety. Delta-beta bands were correlated with anxiety states (Putman, 2011), based on an increased engagement of the delta-beta bands in the orbitofrontal regions and in the anterior cingulate cortex, a phenomenon that has been observed during states of anxiety (Knyazev, 2011). Similarly, a correlation with alpha bands in patients with anxiety has also been observed (Cornelius, Schultz, Brenner, Soloff, \& Ulrich, 1988). Furthermore, the changes in the levels of anxiety experienced by young women during the menstrual cycle are correlated with a specific profile of EEG activity, although there are few extant studies that have focused on this correlation. That said, there are studies that have found high scores for anxiety during the luteal phase compared with the ovulatory phase of the cycle and that have determined that these scores are negatively correlated with theta activity in the left hemisphere and positively correlated with delta, alpha and beta bands in the right hemisphere (Solís-Ortiz \& Corsi-Cabrera, 2002). Additionally, studies have found that premenstrual symptoms induced a negative asymmetry in the alpha band of the frontal region during the luteal phase of the cycle (Baehr, Rosenfeld, Miller, \& Baehr, 2004).

The use of Fourier transform has been extensively used in the analysis of periodic signals in several branches of physics, engineering and biological systems (Bracewell, 1986). Since digital computers appeared, the Fast Fourier Transform (FFT) has been the unique procedure to compute a Fourier Transform in a numerical and approximate form. For the case of brain signals, there is evidence that cyclic variations in somatic, behavioral and affective symptoms in women are temporarily linked to the menstrual cycle, and useful information can be extracted through FFT (Solís-Ortiz, Ramos, Arce, Guevara, \& Corsi-Cabrera, 1994; Solís-Ortiz, Pérez-Luque, \& Gutiérrez-Muñoz, 2012).

In a previous study, we reported the application of a new method of analysis of the EEG signals in a long-time period, namely the entire menstrual cycle, we were able to determine coincident frequencies, and relative phases among brain activity and hormonal signals during the menstrual cycle (Solís-Ortiz, Campos, Felix, \& Obregón, 2009). Since this method is based on an ordinary Fourier Transform of one variable, it cannot be used to determine when the signals be- 
gin and end. In the present study, we present and make use of a short-time Fourier transform method, which provides the frequency of the signal of interest and determines the days when these signals rise and fall. This continuous transformation, called the Gabor transform, which is a short-time Fourier transform very used in time-frequency analysis, can be converted into a discrete short-time Fourier transform by the use of a quadrature with the zeros of the Hermite polynomials as abscissas. In contrast with the usual discrete Fourier transform, this algorithm, predicts more accurately the correct spectrum. We focus on the anxiety signals and its relation with the EEG and the sex hormone signals during the menstrual cycle allowing to identify overlapping regions on the frequency space.

Although a correlation between anxiety and EEG activity during the menstrual cycle has been suggested (Solís-Ortiz \& Corsi-Cabrera, 2002), it is not known when anxiety starts to rise and when it falls and which is its relations with the rise and fall of the EEG and sex hormone signals if they coincide or how they differ with that of the anxiety. The aim of this study was to determine the anxiety frequencies, EEG spectrum frequencies and sex hormone frequencies, and more relevant, when the rise and fall of these frequencies begins and ends during the menstrual cycle and which of them rice or fall approximately together or have an intermediate on opposite behavior.

\section{Methods}

\subsection{Participants}

The current research employed a dataset of young females and the variations of their anxiety scores (Solís-Ortiz \& Corsi-Cabrera, 2002), estrogen and progesterone levels during the menstrual cycle previously reported (Solís-Ortiz, Ramos, Arce, Guevara, \& Corsi-Cabrera, 1994) to illustrate the new method presented here. Briefly, 9 healthy female volunteers aged between 20 and 34 years (mean = $27.11, \mathrm{SD}=4.45)$ take part in a repeated measures study. The participants were university students selected on account of their regular menstrual cycles (28 days \pm 2 ). None of the females were taking any kind of medicine, nor hormonal regimen or manifested acute signs of premenstrual syndrome at the time of the investigation. The factors of convenience and availability guided the selection of the participants.

\subsection{EEG Recording}

The actual investigation also used the same dataset of EEG recording of young females and the variations of their anxiety scores previously reported (Solís-Ortiz \& Corsi-Cabrera, 2002) to exemplify the novel method displayed here. Briefly, a total of 90 sessions of resting-state EEG were recorded in the 9 females with their eyes closed, 10 in each female, three times a week on every second day, at the same time of the day (beginning at $0900 \mathrm{~h}$ and ending at $1000 \mathrm{~h}$ ). EEG recordings stated at the females own convenience, thus the day of menstruation of dif- 
ferent females were randomly distributed over the sessions. The electrodes were placed according to the International 10 - 20 system at F3, F4, C3, C4, P3, P4, O1 and $\mathrm{O} 2$, referred to ipsilateral earlobes. EEG was recorded on a Grass model 16E polygraph set to pass frequencies between 1 and $35 \mathrm{~Hz}$. EEG was captured in a PC computer at sampling rate of $128 \mathrm{~Hz}$ and was analyzed off-line. The stored EEG signals were segmented into non-overlapping $2.048 \mathrm{~s}$ epochs and were carefully inspected offline to eliminate artifacts and were excluded from the analysis. The free-epoch average of each subject from the resting-state EEG (Möcks \& Gasser, 1984) was fast Fourier transformed (FFT) (Bracewell, 1986). Using traditional definitions of bands for characterizing EEG frequency spectra of the normal EEG of a waking adult (Niedermeyer, 2004; Davidson, Jackson, \& Larson, 2000) the absolute power $(\mathrm{Hz})$ was obtained for the following bands: delta, $0.5-4.0 \mathrm{~Hz}$; theta, $4.0-8.0 \mathrm{~Hz}$; alpha1, $8.0-11.0 \mathrm{~Hz}$; alpha2, $11.0-14.0 \mathrm{~Hz}$; beta1, 14.0 - 25.0 $\mathrm{Hz}$; and beta2, $25.0-30.0 \mathrm{~Hz}$, according to the software parameters of clinical use, using quantitative EEG analysis (American EEG Society, 1987; Fisch, 1999; Niedermeyer, 2004). The resulting values were then averaged over all epochs for each period of the cycle and for each subject. The absolute power of the brain signals, as the EEG recording delivered them, was obtained during days $1,3,7,8$, $13,14,20,21,24$ and 25 , thus corresponding to a cycle.

\subsection{Evaluation of Anxiety}

The present investigation also employed a dataset of anxiety scores from the females obtained before of 90 sessions of resting-state EEG recording across of the menstrual cycle previously reported (Solís-Ortiz \& Corsi-Cabrera, 2002), to establish their link with hormonal levels and EEG activity. Briefly, anxiety was evaluated through self-report using the State Anxiety Inventory (STAI) (Speilberg, Gorsush, \& Lushene, 1970) in a standardized version for the Mexican population (Speilberg, Martínez-Urrutia, González-Reigosa, Nalacio, \& Díaz-Guerrero, 1980). This scale, which consists of 40 questions with four possible responses, evaluates feelings of apprehension, tension, nervousness and worry. The STAI clearly differentiates between the temporary condition of state anxiety and the more general and long-standing quality of trait anxiety. In the current investigation, only the state anxiety condition was considered. The scores obtained were averaged and processed to obtain anxiety frequencies according to the method presented and used in this study.

\subsection{Hormones}

The current study also employed a dataset of estrogen and progesterone levels in serum obtained before starting the sessions of EEG across of the menstrual cycle previously reported (Solís-Ortiz, Campos, Felix, \& Obregón, 2009; Solís-Ortiz \& Corsi-Cabrera, 2002). The serum hormone levels were employed to confirm the hormone levels during the menstrual cycle and to establish relations with EEG frequencies and anxiety frequencies. These hormone levels were averaged and 
processed to obtain hormone frequencies according to the method described in the current investigation.

\subsection{Short-Time Fourier Transform}

An omnipresent tool in data analysis is the Fourier transform. The set of data obtained in laboratory tests on a particular variable or signal, for instance EEGs, hormone levels, blood pressure, and so on, can be analyzed by this tool to find recurrence patterns in space or in time as well as the frequencies of the periodic components of the signal. The Fourier transform $F(\omega)$ of the time-dependent signal $u(t)$ is defined by

$$
f(\omega)=\int_{-\infty}^{\infty} \mathrm{e}^{i \omega t} u(t) \mathrm{d} t,
$$

On sometimes it is necessary to know not only the main frequencies but the particular times on which the associated periodic components come in on or leave the signal. This can be done by using a modified Fourier transform called short-time Fourier transform which takes the form

$$
g(t, \omega)=\int_{-\infty}^{\infty} \mathrm{e}^{i \omega t} \mathrm{e}^{-(t-\tau)^{2} / 2} u(\tau) \mathrm{d} \tau,
$$

In this form, this integral transform is also known as the Gabor transform. This transform depends on $\omega$ as well as on $t$. Therefore, we can say that this tool, being a Fourier transform, gives information on the frequencies of the periodic components of the signal along the time. In other words, it renders a map of frequency against time, where the time on which a particular component rise or fall in the signal can be found. These maps of frequency against time are called spectrograms and they have been widely used in many scientific areas (for examples see Hadjidimitriou \& Hadjileontiadis, 2012; Motoyama et al., 2007; Sussillo, Kundaje, \& Anastassiou, 2004; Roy, Montrsor, Abraham, \& Saumet, 1999; Wollemann \& Olaszy, 1977). According to Equation (2), the discrete time dependence of a spectrogram can be obtained by computing the Fourier transforms of the functions

$$
v_{k}(\tau)=e^{-\left(t_{k}-\tau\right)^{2} / 2} u(\tau),
$$

for $k=1,2, \ldots, N$, where $t_{k}$ is the time at which the signal $u\left(t_{k}\right)$ is sampled. Now, to compute the numerical Fourier transform of these functions, we use the XFT, a new algorithm (Campos, Rico-Melgoza, \& Chavez, 2012), which improves the well-known Fast Fourier Transform in the sense that its error is of order $O(1 / N)$ where $\mathrm{N}$ are the number of zeros for the Hermite polynomial. Thus, in contrast to the well known algorithms, this new FFT is able to compute the spectrum for larger periods than the usual FFT with better accuracy and lower number of operations. A version of this algorithm for handling few points has been used elsewhere (Campos \& Figueroa, 2011). The XFT has a logarithmic complexity of $O(N \log N)$ which allows to calculate the spectrum as faster as the Fourier transform (Campos \& Figueroa, 2011). This is the algorithm used to compute the transform (see Equation (2)) and thus, to generate the spectrograms con- 
cerning the EEG, hormone levels and anxiety in this work. Next, we review briefly how to use the XFT. The interested reader can consult a more detailed description elsewhere (Solís-Ortiz, Campos, Felix, \& Obregón, 2009; Campos, Rico-Melgoza, \& Chavez, 2012; Campos \& Figueroa, 2011). Let us denote by $V_{n}$ the vector formed with the $N$ samples of the signal $v(t)$ evaluated at the equidistant times

$$
t_{n}=\left(\frac{\pi}{2 \sqrt{2 N}}\right)(2 n-N-1),
$$

i.e., $V_{n}=v\left(t_{n}\right)$. According to the XFT, an approximation $F=\left(F_{1}, F_{2}, \ldots, F_{N}\right)^{T}$ to the scaled Fourier transform $F(a \omega)$ where $a=4 / \pi$, evaluated at the equidistant points. The scaled frequency can be obtained by

$$
F_{j}=\frac{\pi}{\sqrt{2 N}} \mathrm{e}^{i \pi\left(\frac{(N-1)^{2}}{2 N}-\frac{N-1}{N}(j-1)\right)} f f t(\tilde{V})_{j^{\prime}}
$$

Here, $F_{j}$ approximates to the Fourier transform $F(\omega)$ evaluated at the scaled frequency $a \omega_{p}$ i.e.,

$$
F_{j} \cong f\left(a \omega_{j}\right),
$$

and $f f t(\tilde{V})$ stands for the output of any standard FFT algorithm applied to the vector whose elements are given by

$$
\tilde{v}_{n}=\mathrm{e}^{-i \pi \frac{N-1}{N} n} v\left(t_{n}\right)
$$

This algorithm is based on the approximation of a square-integrable function by linear combinations of discrete Hermite functions (Campos, Rico-Melgoza, \& Chavez, 2012). Because of this, it gives accurate results for the computation of the Fourier transform of rapidly decreasing functions evaluated at the frequencies $\omega_{i}$. Therefore, according to the above results, to compute an approximation to the short-time Fourier transform shown in Equation (2) of a set of $N$ samples of a signal $u(t)$ we give the following pseudo code:

INPUT: $t_{k}$ and $U=\left(u\left(t_{1}\right), u\left(t_{2}\right), \cdots, u\left(t_{n}\right)\right) T$

OUTPUT: $F_{k}=\left(F_{1 k}, F_{2 k}, \cdots, F_{N k}\right) T$

1) Get $N$

2) Set the equidistant points

$$
t_{n}=\left(\frac{\pi}{2 \sqrt{2 N}}\right)(2 n-N-1) \text { for } n=1,2, \ldots, N
$$

3) Set the modified spectral function

$$
\tilde{V}_{n}=\mathrm{e}^{-i \pi \frac{N-1}{N} n} \mathrm{e}^{-\frac{\left(t_{k}-t_{n}\right)^{2}}{2}} u\left(t_{n}\right) \text { for } n=1,2, \ldots, N
$$

4) Set the fft of the modified function

5) Obtain $F_{k}$

$$
F_{n}=\frac{\pi}{\sqrt{2 N}} \mathrm{e}^{i \pi\left(\frac{(N-1)^{2}}{2 N}-\frac{N-1}{N}(n-1)\right)} f f t\left(\tilde{V}_{n}\right)
$$


Usually, a signal is sampled at arbitrary equidistant points. Therefore, some processing on these data has to be made in order to apply this algorithm. If the signal is periodic, as in our case, the easiest processing is to interpolate the data with trigonometric functions and then to evaluate this interpolation at the asymptotic Hermite zeros shown in Equation (4).

Before going further we give an example. Assume that the signal is given by

$$
f(t)=\left\{\begin{array}{cc}
8 \sin (1.5 t) & t<-15 \\
20 \sin (4.5 t) & -15<t<20 \\
12 \sin (12.5 t) & t>20
\end{array}\right.
$$

This signal is composed of three functions: a component of frequency 1.5 which falls at $t=-15$, a second component, of frequency 4.5 , that rises at $t=-15$ and falls at $t=20$ and a third component, of frequency 2.5 , that rises at $t=20$. Note that the Fourier transform (see Equation (1)) of this signal, computed by using the XFT and shown in Figure 1, retrieves the three frequencies of the components composing this signal, however, there is nothing about the times of rise and fall of the components. To know, to some extent, the time on which a specific component is switched on or off we can use the Gabor transform (see Equation (2)). Figure 2 shows the output of this calculation. Note that in this case the times of rise and fall are more precise than the values of the frequencies.

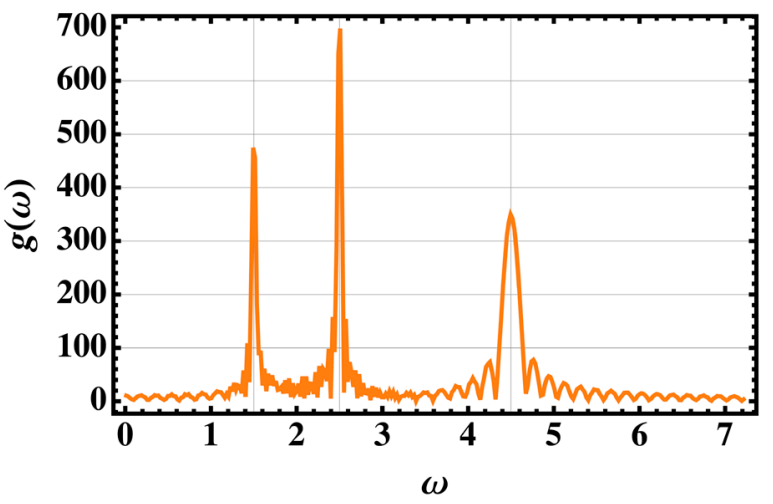

Figure 1. Fourier transform of the function given by Equation (8).

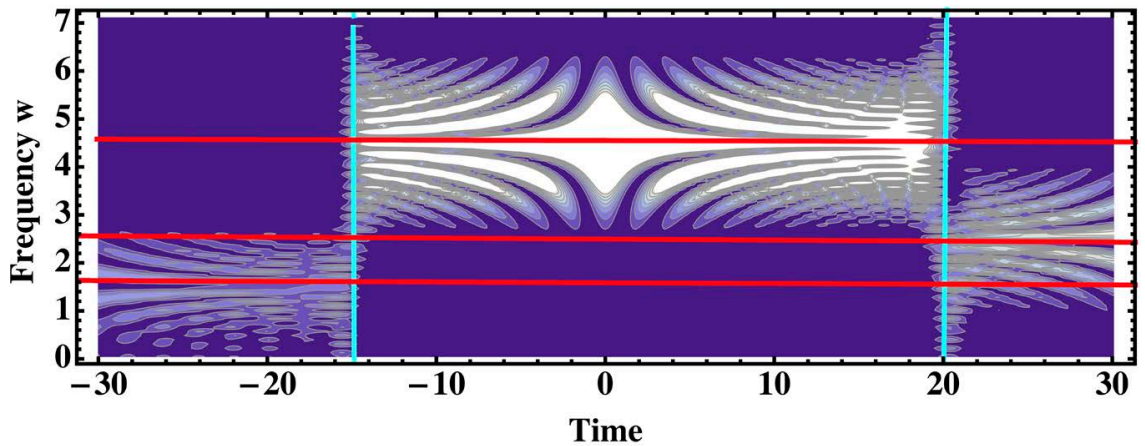

Figure 2. Spectrogram of the Equation (8) obtained with the Gabor transform (see Equation (2)). The red lines are centered at the frequencies 1.5, 2.5 and 4.5 respectively, and the cyan lines are centered at the times of rise and fall. 
This is due to the uncertainty principle. For analysis, particularly for coincident frequencies, it was considered values greater than 0.20 in the $y$ axis, as a criterion to facilitate proper interpretation.

\subsection{Statistical Analysis}

In the current study, the statistical analysis used to establish the comparisons was previously reported (Solís-Ortiz \& Corsi-Cabrera, 2002). Briefly, to perform this analysis, it was employed STATISTICA for Windows 8 (StatSolf, Inc.). A way ANOVAs for repeated measures designs was computed with 10 recording days as factor separately for each band (delta, theta, alpha1, alpha2, beta1 and beta2). Post hoc comparisons between means were made using Tukey test. Since anxiety scores did not show normal distribution, Friedman test for repeated measures was computed with all anxiety scores, estrogen and progesterone levels measured during the 90 sessions, 10 in each woman. Post hoc comparisons between median were made using Wilcoxon Signed-Rank test. In all cases a $p<$ 0.05 was considered as significant.

\section{Results}

\subsection{EEG Spectrum and Menstrual Cycle}

The results reported previously (Solís-Ortiz \& Corsi-Cabrera, 2002) showed that the ANOVA analysis revealed significant main effects for delta $(F(9)=2.38, p=$ $0.01)$, theta $(F(9)=1.99, p=0.03)$, alpha1 $(F(9)=3.09, p=0.002)$, alpha2 $(F(9)$ $=5.44, p=0.001)$, beta1 $(F(9)=3.06, p=0.002)$ and beta2 $(F(2)=2.61, p=$ 0.006 ) bands at alpha $=9.95$, indicating that women differed in the absolute power of their EEG and that the differences varied by band during the 10 days of the menstrual cycle.

\subsection{Anxiety}

The previously described outcome (Solís-Ortiz \& Corsi-Cabrera, 2002) indicated that although anxiety scores were within the normal range, comparisons between means demonstrated that anxiety levels were higher during the luteal phase of the menstrual cycle $(t=2.26, p=0.02)$ compared to ovulation. Even so, anxiety scores transformed into frequencies revealed relevant information which is described below.

\subsection{Hormones}

The previously described outcome (Solís-Ortiz, Campos, Felix, \& Obregón, 2009) indicated that the estrogen levels of participants displayed significantly change over the menstrual cycle $\left(X^{2}(9)=74.08, p=0.001\right)$. Comparisons post hoc demonstrated that estrogen levels were higher during the days 14 of the menstrual cycle $(t=-34.29, p=0.001)$ compared with the day lof menstruation, when the estrogen levels are lower. The progesterone levels of females displayed significantly change over the menstrual cycle $\left(X^{2}(9)=79.70, p=0.001\right)$. Com- 
parisons post hoc revealed that progesterone levels were higher during the days 21 of the menstrual cycle $(t=109.04, p=0.001)$ compared with the day lof menstruation, when the progesterone levels are lower.

\subsection{Coincident Frequencies}

The figures show the dominant frequencies in the hormone level signals (progesterone and estrogens) and anxiety signal followed by the main frequencies of the averaged absolute power of the brain signals during the menstrual cycle.

The colored peaks are centered at 1,2,3 or 4 . This means a frequency of one a month, a frequency of 2 a $1 / 2$ month, a frequency of 3 a $1 / 3$ month and frequency 4 a 1/4 month, respectively. The dominant frequencies occur at the higher peak. In all cases, frequency 1 was not considered for analysis because this frequency occurs every month. The intensity values on the y-axis, as shown in Figure 1 and Figure 2, were normalized.

The anxiety exhibited a frequency of 3 , that is, it occurred every ten days (Figure 3). The progesterone, theta, alpha1, alpha2, beta1 and beta2 also exhibited a frequency of 3 . The progesterone, estrogens, delta, alpha1 and alpha 2 exhibited a frequency of 2, that is, they occurred every 14 days. The estrogens, delta, theta, beta 1 and beta 2 exhibited a frequency of 4 , which indicates that they occurred every seven days (Figure 4). This figure also presents a visual depiction of anxiety (green) with respect to the frequencies of progesterone, estrogens, delta, theta, alpha1, alpha2, beta1 and beta2, thus revealing the coincidence of anxiety with these frequencies. Upon examination of this figure, it is evident that anxiety frequency 3 coincides with frequency $3 \mathrm{~s}$ of progesterone, theta, alpha1, alpha2, beta1 and beta2.

\subsection{Spectrograms}

Spectrogram analyses reveal the rise and fall of frequencies during the 28-day period. In Figure 5, which presents the results of the anxiety signal and the hormone signals from spectrograms, the signals that occur first in the 28-day period can be detected.

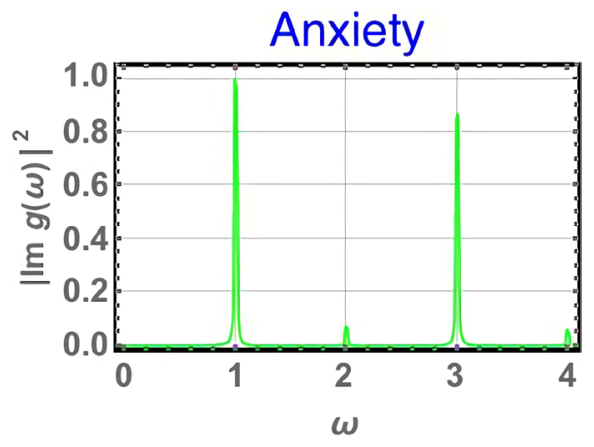

Figure 3. Principal frequencies of the intensity of anxiety over a period of 28 days. Anxiety frequency 1 corresponds to 28 days, anxiety frequency 2 corresponds to 14 days, anxiety frequency 3 corresponds to 10 days and anxiety frequency 4 corresponds to 7 days. Note that anxiety exhibited the relevant frequency of 3 . 

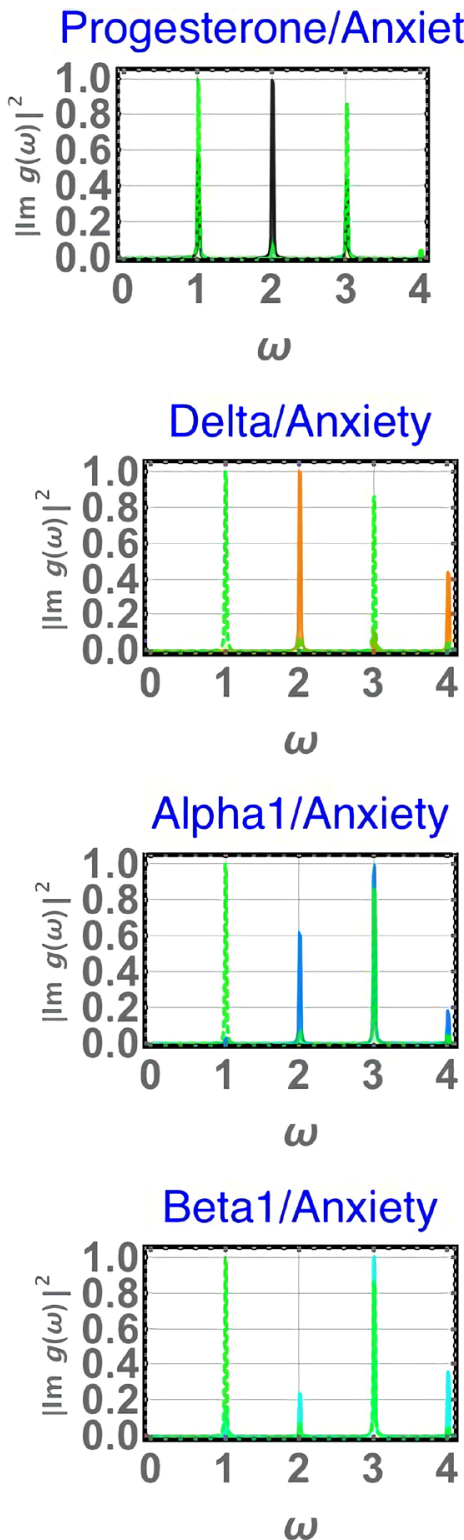

Estrogen/Anxiety

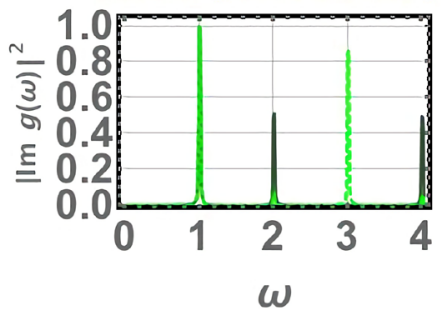

Theta/Anxiety

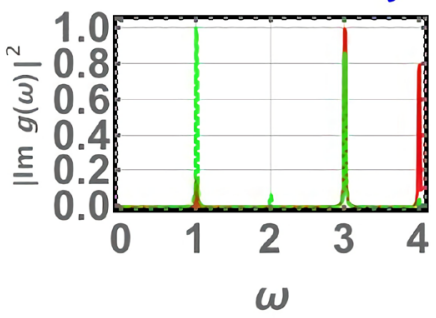

Alpha2/Anxiety
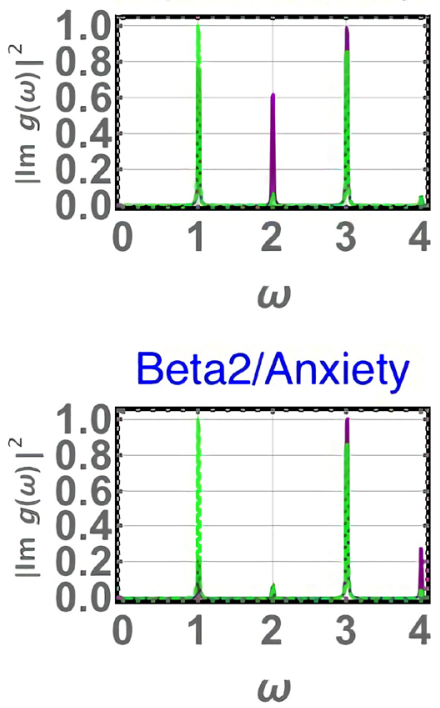

Figure 4. Principal frequencies of the spectrum of anxiety compared with those of the progesterone and brain signals. Anxiety is plotted in green. For delta and estrogen the frequency 3 relevant of anxiety is not present. The frequency lis present in most of these signals and it corresponds to the menstrual cycle. The rest of the frequencies, 2, 3 and 4, correspond to 14,10 , and 7 days, respectively.

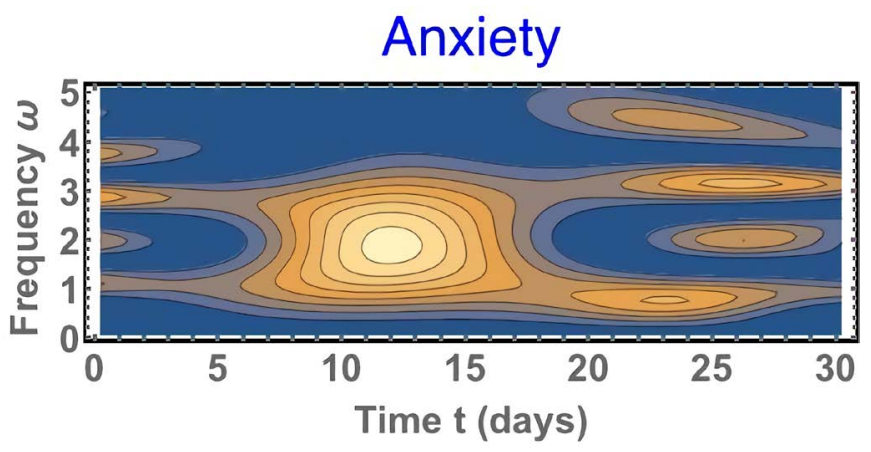



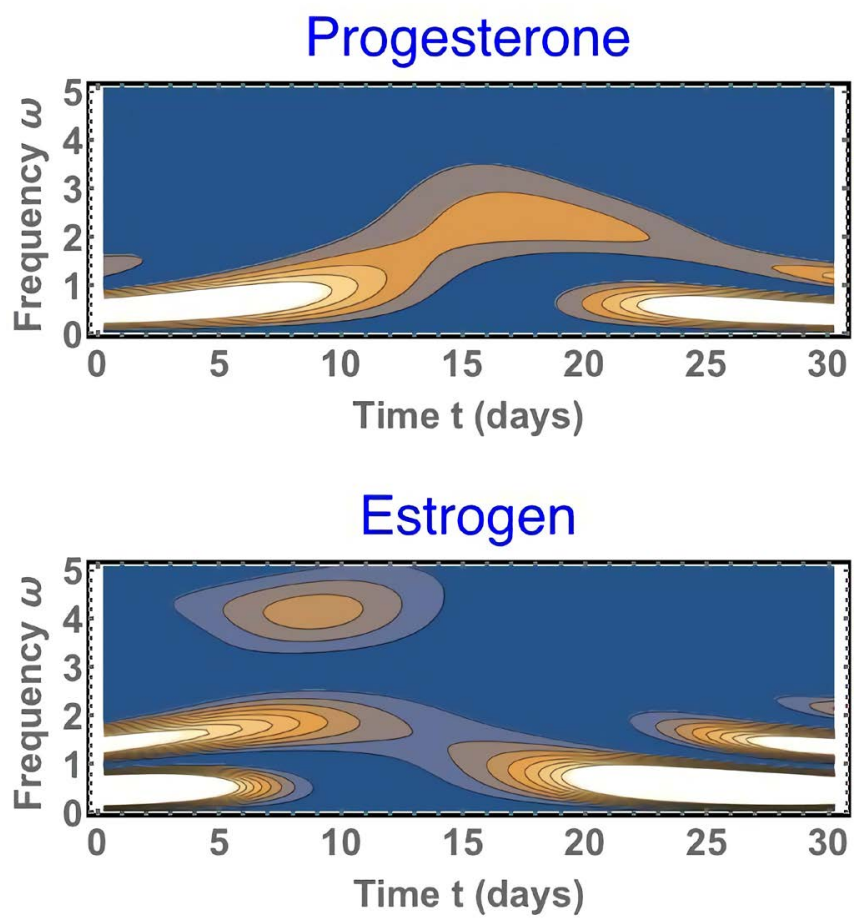

Figure 5. Spectrograms of anxiety, progesterone and estrogen showing the rise and fall of the principal frequencies of each of these signals over a period of 28 days.

Figure 6 displays the spectrograms of the brain signals. To better understand the rise and fall of frequencies in these spectrograms, Figure 7 depicts the frequencies 2, 3 and 4 with the colors green, yellow and blue, respectively. This helps to indicate when the frequencies began to rise and when they fell for each of the three signals anxiety, hormones and brain signals. Anxiety frequency 3 rose on day 8 and fell on day 18 of the cycle. Around this same time period, frequencies 2 and 4 of estrogens, frequencies 2 and 3 of delta, and frequencies 2 and 3 of alphal began to rise between days 1and 5 and fall between days 10 and 15 . Anxiety frequency 3 is also partially coincident with the rise of frequencies 2 and 3 of progesterone and with frequencies 3 and 4 of theta, which began to rise between days 10 and 15 and fall between days 21 and 25 .

When anxiety frequency 3 began its fall (near day 18), frequency 2 of progesterone and frequencies 3 and 4 of theta continued their rise until falling between days 22 and 25 of the cycle. Furthermore, frequencies 2 and 3 of alpha2 and frequencies 3 and 4 of beta1 and beta2 began to rise between days 15 and 21 and fell between days 25 and 28. Only frequency 2 of alpha2 continued to rise until its fall on day 7.

\section{Discussion}

The analysis of the 90 EEG records made in this study for each signal shows, for the first time, that anxiety frequency exhibited coincident frequencies with estrogen and progesterone as well as with EEG frequencies and that this anxiety frequency was also related with the rise and fall of estrogen, progesterone and 

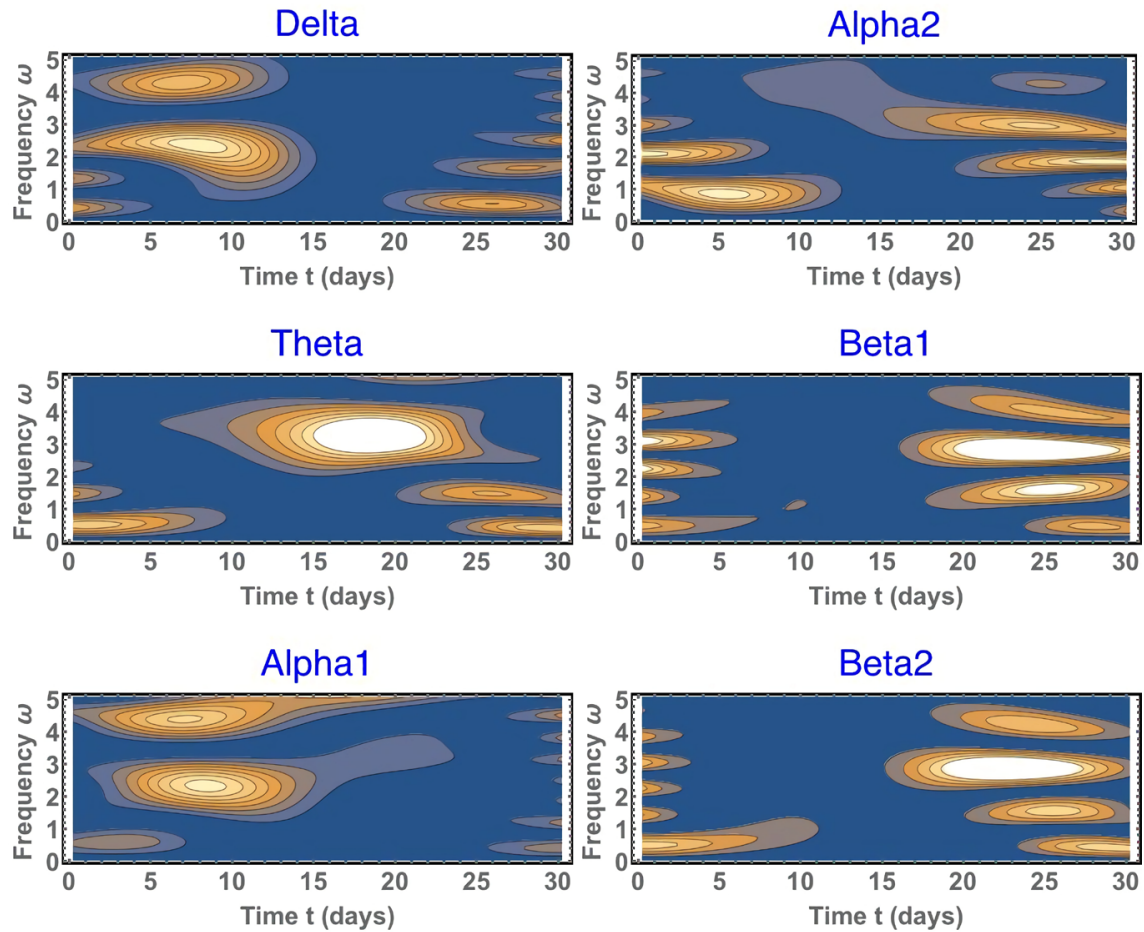

Figure 6. Spectrograms of the brain signals showing the rise and fall of the principal frequencies; delta, theta, alpha1, alpha2, beta1and beta2 during the menstrual cycle.

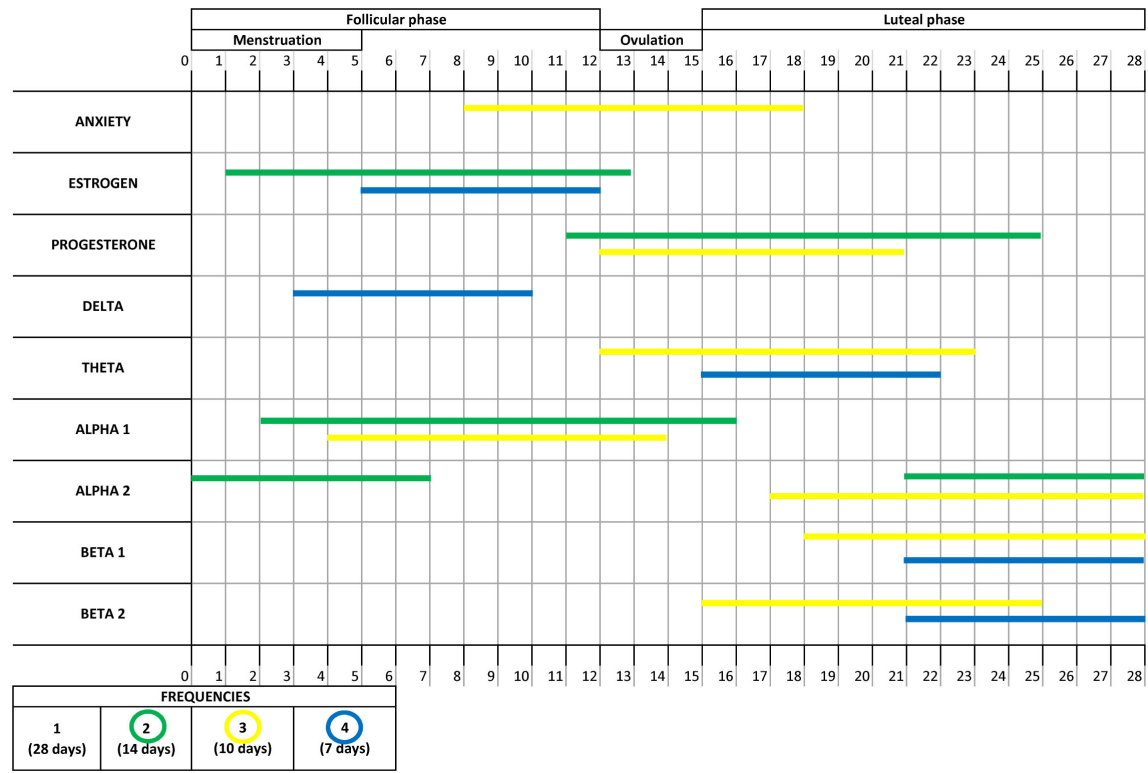

Figure 7. Time-line of the rise and fall of EEG frequencies, anxiety, estrogen and progesterone during the menstrual cycle.

EEG frequencies during a menstrual cycle. To obtain these results a short-time Fourier transformation was applied. The result seems to indicate the degree to which certain brain signals couple with specific sex hormones and anxiety during a 28-day period. Some studies have reported that anxiety was minimal around ovulation, gradually increased soon after ovulation, and reached its maximum 
during the last five days of the luteal phase before, diminishing once again (Nillni, Toufexis, \& Rohan, 2011; Solís-Ortiz \& Corsi-Cabrera, 2002). Our results, derived from the application of the method presented herein, contributes to add new information about the rise and fall as well as the coincident frequencies of the various hormones, levels of anxiety and EEG spectrum. In the cases presented here, anxiety frequency 3 , which occurred every ten days, rose on day 8 and fell on day 18 of the cycle. Around this same period, the frequencies of estrogens, delta, and alpha1, began to rise between days 1 and 5 and fall between days 10 and 15. These results indicate that anxiety frequency 3 begins to emerge short after the physiological levels of estrogen begin to rise, reaching their highest peak near day 14 of the ovulatory phase of the cycle, while progesterone begins to emerge close to day 14 and reaches its elevated peak around day 21, in the early luteal phase of the regular menstrual cycle. Fluctuations in estrogen during the menstrual cycle affect EEG activity in young women (Solís-Ortiz, Ramos, Arce, Guevara, \& Corsi-Cabrera, 1994) and also affect anxiety (Solís-Ortiz \& Corsi-Cabrera, 2002). Estrogen functions as a multipurpose brain messenger that can interact with the neurotransmitter system in critical brain nuclei and can facilitate function via gene expression and transmitter-gated ion channels. Estrogen action is mediated through estrogen receptors $\alpha$ and $\beta$, which are widely distributed throughout the brain (Ostlund, Keller, \& Hurd, 2003). Receptors for estrogen have been localized in the amygdala, a region sensitive to estrogen, and therefore, the amygdala might play a role in anxiety (ter Horst, 2010), in accordance with our results. The partial coincidences of the periods of anxiety frequency with those of the frequencies of delta and alpha found in the present study suggest a state of low cerebral activation related to estrogens. The influence of estrogens in the nervous system and on mood have been noted in several studies (Albert, Pruessner, \& Newhouse, 2015; Toffoletto, Lanzenberger, Gingnell, Sundstrom-Poromaa, \& Comasco, 2014; Bayer, Schultz, Gamer, \& Sommer, 2014; Wise, 2002) that have suggested an anxiolytic action of estrogens. A study using brain imaging techniques demonstrated significant differences in the activation of arousal circuitry in adult women with attenuation during ovulation and increased activation during the early follicular menstrual cycle phase (Goldstein et al., 2005). In our study, when the anxiety frequency rose, the frequency of estrogen and the slow frequencies of brain activity also increased, perhaps to mitigate the effects of anxiety on brain activity.

Interestingly, our results also showed that the anxiety frequency 3 exhibited a profile that nearly coincides with the dominant frequency 3 of progesterone, theta and alpha1. The spectrograms reveal that anxiety frequency 3 was also partially coincident with the rise in the frequencies of progesterone and with the frequencies of theta, which began to rise between days 10 and 15 and then fell between days 21 and 25 . These findings are supported with evidence about the effects of progesterone on the brain. Accumulated evidence indicates that progesterone induces negative moods that are most likely mediated via the action of the progesterone metabolites binding to the GABAA receptor complex, thereby 
potentiating GABAergic inhibitory mechanisms and inhibiting the inhibitory neurons that may promote disinhibition and, hence, excitability (Majewska \& Schwartz, 1987; Eser, Baghai, Schüle, Nothdurfter, \& Rupprecht, 2008; Birzniece et al., 2006; Wang, 2011). The modulation of the GABAA receptor by progesterone and its metabolite at low concentrations induces moderate to severe adverse mood changes (Bäckström et al., 2011), while high concentrations may act as an anxiolytic (Bitran, Purdy, \& Kellogg, 1993) or sedative agent (van Broekhoven et al., 2007). Theta activity, which is involved in the emotional regulation (Niedermeyer, 2004; Knyazev, 2007; Cornwell, Arkin, Overstreet, Carver, \& Grillon, 2012), may reflect the anxiolytic effects attributed to progesterone.

Our results also show that, when the anxiety frequency began to fall (near day 18), frequency 2 of progesterone and the frequencies of theta continued until their fall between days 22 and 25 of the cycle. During this brief period, it has been determined that the physiological levels of progesterone are initially high and then begin to decrease. These frequency brain profiles obtained here could reflect anxiolytic effects of progesterone (van Wingen, Ossewaarde, Bäckström, Hermans, \& Fernández, 2011) as it has been suggested that higher concentrations of progesterone/allopregnanolone in women decrease amygdala activity, similar to that observed during benzodiazepine treatment, which exhibited calming anxiolytic effects (Eser, Baghai, Schüle, Nothdurfter, \& Rupprecht, 2008). In addition, in the current investigation the anxiety frequency 3 also coincided with the frequency 3 of alpha2, beta1 and beta2, but in contrast, these frequencies rose when the anxiety frequency began to fall (on day 18). Specifically, the spectrograms calculated here revealed that the frequencies of alpha2 and the frequencies of beta1 and beta2 began to rise between days 15 and 21 and fell between days 25 and 28. These profiles could reflect the paradoxical activating effects of neuroactive steroids related with progesterone metabolites and their action on neuronal excitability (Bäckström et al., 2011), and they may also reflect the withdrawal syndrome caused by the sudden drop in progesterone (Majewska \& Schwartz, 1987; Löfgren, Johansson, Meyerson, Turkmen, \& Bäckström, 2009). Some studies have found high power of fast activity associated with arousal (Steriade, 2004), anxiety (Solís-Ortiz \& Corsi-Cabrera, 2002; Putman, 2011; Knyazev, 2011) emotional reactivity (Tumyalis \& Aftanas, 2014) and depression in females (Solís-Ortiz, Pérez-Luque, \& Pacheco-Zavala, 2012), suggesting increased emotive arousal. A study demonstrated significant increased amygdala reactivity during the luteal phase of the menstrual cycle in women with premenstrual dysphoric disorder and high scores on trait anxiety (Gingnell, Morell, Bannbers, Wikström, \& Sundström-Poromaa, 2012).

The findings of the present study have some implications for clinical practice. Some women may be prone to manifest symptoms of anxiety probably due to hormonal influence and other factors that confer risk to anxiety. The proposed method could have important therapeutic implications. Specific treatments targeted and modifying brain activity could be developed, especially for those indi- 
viduals who do not respond well to conventional treatment. Pharmacological and/or psychological treatments should take into account that anxiety induces changes in EEG signals and that they coincide with sex hormones.

\section{Conclusion}

In the present work, we used a new algorithm that predicts accurately the correct spectrum of brain signals. The present findings demonstrate for the first time, with relation to women, that the frequency of anxiety coincides with some frequencies of sex hormones and EEG. More interesting the rise and fall of anxiety frequency coincide and can relate with the rise and fall of the EEG spectrum and sex hormones. These results were possible by means of our proposal of considering and analyzing these signals in a long-time period, namely the menstrual cycle; for this purpose, a novel and appropriate analytical tool was introduced. This methodology could be useful as a diagnostic tool for severe anxiety disorders.

\section{Acknowledgements}

This research was funded by the Transversal Projects for Research of the Universidad of Guanajuato, Campus León and by a grant from DAIP of the Universidad of Guanajuato. We are grateful to Octavio Obregón and María Corsi-Cabrera for suggestions and comments that enriched the discussion of this paper.

\section{Conflicts of Interest}

The authors declare no conflicts of interest regarding the publication of this paper.

\section{References}

Albert, K., Pruessner, J., \& Newhouse, P. (2015). Estradiol Levels Modulate Brain Activity and Negative Responses to Psychosocial Stress across the Menstrual Cycle. Psychoneuroendocrinology, 59, 14-24. https://doi.org/10.1016/j.psyneuen.2015.04.022

American EEG Society (1987). Statement on the Clinical Use of Quantitative EEG Analysis. Journal Clinical Neurophysiology, 4, 75. https://doi.org/10.1097/00004691-198701000-00005

Bäckström, T., Andersson, A., Andreé, L., Birzniece, V., Bixo, M., Björn, I., Haage, D., Isaksson, M., Johansson, I. M., Lindblad, C., Lundgren, P., Nyberg, S., Odmark, I. S., Strömberg, J., Sundström-Poromaa, I., Turkmen, S., Wahlström, G., Wang, M., Wihlbäck, A. C., Zhu, D., \& Zingmark, E. (2003). Pathogenesis in Menstrual Cycle-Linked CNS Disorders. Annals New York Academic Sciences, 1007, 42-53. https://doi.org/10.1196/annals.1286.005

Bäckström, T., Bixo, M., Johansson, M., Nyberg, S., Ossewaarde, L., Ragagnin, G., Savic, I., Strömberg, J., Timby, E., van Broekhoven, F., \& van Wingen, G. (2014). Allopregnanolone and Mood Disorders. Progress Neurobiology, 113, 88-94. https://doi.org/10.1016/j.pneurobio.2013.07.005

Bäckström, T., Haage, D., Löfgren, M., Johansson, I. M., Strömberg, J., Nyberg, S., 
Andréen, L., Ossewaarde, L., van Wingen, G. A., Turkmen, S., \& Bengtsson, S. K. (2011). Paradoxical Effects of GABA-A Modulators May Explain Sex Steroid Induced Negative Mood Symptoms in Some Persons. Neuroscience, 191, 46-54.

https://doi.org/10.1016/j.neuroscience.2011.03.061

Baehr, E., Rosenfeld, P., Miller, L., \& Baehr, R. (2004). Premenstrual Dysphoric Disorder and Changes in Frontal Alpha Asymmetry. International Journal Psychophysiology, 52, 159-167. https://doi.org/10.1016/j.ijpsycho.2003.06.002

Basar, E., \& Güntekin, B. (2008). A Review of Brain Oscillations in Cognitive Disorders and the Role of Neurotransmitters. Brain Research, 1235, 172-193. https://doi.org/10.1016/j.brainres.2008.06.103

Bayer, J., Schultz, H., Gamer, M., \& Sommer, T. (2014). Menstrual-Cycle Dependent Fluctuations in Ovarian Hormones Affect Emotional Memory. Neurobiology of Learning Memory, 110, 55-63. https://doi.org/10.1016/j.nlm.2014.01.017

Becker, D., Creutzfeldt, O. D., Schwibbe, M., \& Wuttke, W. (1982). Changes in Physiological, EEG and Psychological Parameters in Women during the Spontaneous Menstrual Cycle and Following Oral Contraceptives. Psychoneuroendocrinology, 7, 75-90. https://doi.org/10.1016/0306-4530(82)90057-9

Birzniece, V., Türkmen, S., Lindblad, C., Zhu, D., Johansson, I. M., Bäckström, T., \& Wahlström, G. (2006). GABA(A) Receptor Changes in Acute Allopregnanolone Tolerance. European Journal Pharmacology, 535, 125-134.

https://doi.org/10.1016/j.ejphar.2006.01.059

Bitran, D., Purdy, R. H., \& Kellogg, C. K. (1993). Anxiolytic Effect of Progesterone Is Associated with Increases in Cortical Allopregnanolone and GABAA Receptor Function. Pharmacology Biochemistry Behavior, 45, 423-428. https://doi.org/10.1016/0091-3057(93)90260-Z

Blum, I., Lerman, M., Misrachi, I., Nordenberg, Y., Grosskopf, I., Weizman, A., Levy-Schiff, R., Sulkes, J., \& Vered, Y. (2004). Lack of Plasma Norepinephrine Cyclicity, Increased Estradiol during the Follicular Phase, and of Progesterone and Gonadotrophins at Ovulation in Women with Premenstrual Syndrome. Neuropsychobiology, 50, 10-15. https://doi.org/10.1159/000077935

Bracewell, R. (1986). The Fourier Transform and Its Applications. New York: McGraw Hill.

Buzsáki, B. (2006). Rhythms of the Brain. New York: Oxford University Press. https://doi.org/10.1093/acprof:oso/9780195301069.001.0001

Campos, R. G., \& Figueroa, J. (2011). A Fast Algorithm for the Linear Canonical Transform. Signal Process, 9, 1444-1447. https://doi.org/10.1016/j.sigpro.2010.07.007

Campos, R. G., Rico-Melgoza, J., \& Chavez, E. (2012). A New Formulation of the Fast Fractional Fourier Transform. SIAM Journal Science Computational, 34, A1110-1125. https://doi.org/10.1137/100812677

Cornelius, J. R., Schultz, S., Brenner, R. P., Soloff, P. H., \& Ulrich, R. H. (1988). Changes in EEG Mean Frequency Associated with Anxiety and with Amphetamine Challenge in BPD. Biological Psychiatry, 24, 587-594. https://doi.org/10.1016/0006-3223(88)90169-2

Cornwell, B. R., Arkin, N., Overstreet, C., Carver, F. W., \& Grillon, C. (2012). Distinct Contributions of Human Hippocampal Theta to Spatial Cognition and Anxiety. Hippocampus, 22, 1848-1859. https://doi.org/10.1002/hipo.22019

Davidson, R. J., Jackson, D. C., \& Larson, C. L. (2000). Human Electroencephalography. In: J. T. Cacioppo, L. G. Tassinary, \& G. G. Bernston (Eds.), Handbook of Psychophysiology (pp. 27-52). New York: Cambridge University Press. 
Dennerstein, L., Lehert, P., \& Heinemann, K. (2012). Epidemiology of Premenstrual Symptoms and Disorders. Menopause International, 18, 48-51. https://doi.org/10.1258/mi.2012.012013

Dueñas, J. L., Lete, I., Bermejo, R., Arbat, A., Pérez-Campos, E., Martínez-Salmeán, J., Serrano, I., Doval, J. L., \& Coll, C. (2011). Prevalence of Premenstrual Syndrome and Premenstrual Dysphoric Disorder in a Representative Cohort of Spanish Women of Fertile Age. European Journal of Obstetrics Gynecology and Reproductive Biology, 156, 72-77. https://doi.org/10.1016/j.ejogrb.2010.12.013

Eser, D., Baghai, T. C., Schüle, C., Nothdurfter, C., \& Rupprecht, R. (2008). Neuroactive Steroids as Endogenous Modulators of Anxiety. Current Pharmaceutical Design, 14, 3525-3533. https://doi.org/10.2174/138161208786848838

Fisch, B. J. (1999). Special Methods of Analysis and Recording. In B. J. Fisch, \& S. Spehlmann's (Eds.), EEG Primer. Basic Principles of Digital and Analog EEG (pp. 124-134). Amsterdam: Elsevier Science.

Ford, O., Lethaby, A., Roberts, H., \& Mol, B. W. (2012). Progesterone for Premenstrual Syndrome. Cochrane Database System Review, No. 3, CD003415. https://doi.org/10.1002/14651858.CD003415.pub4

Gingnell, M., Morell, A., Bannbers, E., Wikström, J., \& Sundström-Poromaa, I. (2012). Menstrual Cycle Effects on Amygdala Reactivity to Emotional Stimulation in Premenstrual Dysphoric Disorder. Hormonal Behavioral, 62, 400-406.

https://doi.org/10.1016/j.yhbeh.2012.07.005

Girdler, S. S., Straneva, P. A., Light, K. C., Pedersen, C. A., \& Morrow, A. L. (2001). Allopregnanolone Levels and Reactivity to Mental Stress in Premenstrual Dysphoric Disorder. Biological Psychiatry, 49, 788-797. https://doi.org/10.1016/S0006-3223(00)01044-1

Goldstein, J. M., Jerram, M., Poldrack, R., Ahern, T., Kennedy, D. N., Seidman, L. J., \& Makris, N. (2005). Hormonal Cycle Modulates Arousal Circuitry in Women Using Functional Magnetic Resonance Imaging. Journal of Neuroscience, 25, 9309-9316. https://doi.org/10.1523/JNEUROSCI.2239-05.2005

Gonda, X., Telek, T., Juhász, G., Lazary, J., Vargha, A., \& Bagdy, G. (2008). Patterns of Mood Changes throughout the Reproductive Cycle in Healthy Women without Premenstrual Dysphoric Disorders. Progress in Neuro-Psychopharmacology and Biological Psychiatry, 32, 1782-1788. https://doi.org/10.1016/j.pnpbp.2008.07.016

Hadjidimitriou, S. K., \& Hadjileontiadis, L. J. (2012). Toward an EEG-Based Recognition of Music Liking Using Time-Frequency Analysis. IEEE Transactions on Biomedical Engineering, 59, 3498-3510. https://doi.org/10.1109/TBME.2012.2217495

Hantsoo, L., \& Epperson, C. N. (2015). Premenstrual Dysphoric Disorder: Epidemiology and Treatment. Current Psychiatry Reports, 17, 87.

https://doi.org/10.1007/s11920-015-0628-3

Hausmann, M., \& Güntürkün, O. (2008). Steroid Fluctuations Modify Functional Cerebral Asymmetries: The Hypothesis of Progesterone-Mediated Interhemispheric Decoupling. Neuropsychologia, 38, 1362-1374.

https://doi.org/10.1016/S0028-3932(00)00045-2

Hausmann, M., Hamm, J. P., Waldie, K. E., \& Kirk, I. J. (2013). Sex Hormonal Modulation of Interhemispheric Transfer Time. Neuropsychologia, 51, 1734-7141. https://doi.org/10.1016/j.neuropsychologia.2013.05.017

Holmes, G., \& R. Khazipov, R. (2007). Basic Neurophysiology and the Cortical Basic of EEG. In A. S. Blum, \& S. B. Rutkove (Eds.), The Clinical Neurophysiology Primer (pp. 19-33). Totowa, NJ: Humana Press Inc. https://doi.org/10.1007/978-1-59745-271-7_2 
Jackson, A. F., \& Bolger, D. J. (2014). The Neurophysiological Base of EEG and EEG Measurement: A Review for the Rest of Us. Psychophysiology, 51, 1061-1071. https://doi.org/10.1111/psyp.12283

Katzenellenbogen, B. S., Choi, I., Delage-Mourroux, R., Ediger, T. R., Martini, P. G., Montano, M., Sun, J., \& Weis, K. (2000). Molecular Mechanisms of Estrogen Action: Selective Ligands and Receptor Pharmacology. Journal Steroid Biochemistry and Molecular Biology, 74, 279-285. https://doi.org/10.1016/S0960-0760(00)00104-7

Knyazev, G. G. (2007). Motivation, Emotion, and Their Inhibitory Control Mirrored in Brain Oscillations. Neuroscience Biobehavioral Review, 31, 377-395. https://doi.org/10.1016/j.neubiorev.2006.10.004

Knyazev, G. G. (2011). Cross-Frequency Coupling of Brain Oscillations: An Impact of State Anxiety. International Journal Psychophysiology, 80, 236-245.

https://doi.org/10.1016/j.ijpsycho.2011.03.013

Le Mellédo, J. M., \& Baker, G. (2004). Role of Progesterone and Other Neuroactive Steroids in Anxiety Disorders. Expert Review Neurotherapeutics, 4, 851-860. https://doi.org/10.1586/14737175.4.5.851

Löfgren, M., Johansson, I. M., Meyerson, B., Turkmen, S., \& Bäckström, T. (2009). Withdrawal Effects from Progesterone and Estradiol Relate to Individual Risk-Taking and Explorative Behavior in Female Rats. Physiology Behavioral, 96, 91-97. https://doi.org/10.1016/j.physbeh.2008.08.015

Lopes da Silva, F. (2010). EEG: Origin and Measurement. In C. Mulert, \& L. Lemieux (Eds.), EEG-fMRI: Physiological Basic, Technique, and Applications (pp. 19-38). New York: Springer. https://doi.org/10.1007/978-3-540-87919-0_2

Majewska, M. D., \& Schwartz, R. D. (1987). Pregnenolone-Sulfate: An Endogenous Antagonist of the Gamma-Aminobutyric Acid Receptor Complex in Brain? Brain Research, 404, 355-360. https://doi.org/10.1016/0006-8993(87)91394-1

Möcks, J., \& Gasser, T. (1984). How to Select Epochs of the EEG for Quantitative Analysis. Electroencephalography Clinical Neurophysiology, 58, 89-92.

https://doi.org/10.1016/0013-4694(84)90205-0

Motoyama, S., Saito, R., Maruyama, K., Okuyama, M., Sasaki, K., Wako, M., Kitamura, A., \& Ogawa, J. (2007). Sound Spectrogram Analysis in Patients Receiving Kawahara's Surgical Voice Restoration for Advanced Carcinoma of the Hypopharynx and Cervical Esophagus. Disease Esophagus, 20, 42-46.

https://doi.org/10.1111/j.1442-2050.2006.00625.x

Niedermeyer, E. (2004). The Normal EEG of the Waking Adult. In E. Niedermeyer, \& L. F. H. Da Silva (Eds.), Electroencephalography: Basic Principles, Clinical Applications, and Related Fields (pp. 131-152). Baltimore, MD: Williams \& Wilkins.

Nillni, Y. I., Toufexis, D. J., \& Rohan, K. J. (2011). Anxiety Sensitivity, the Menstrual Cycle, and Panic Disorder: A Putative Neuroendocrine and Psychological Interaction. Clinical Psychological Review, 31, 1183-1191. https://doi.org/10.1016/j.cpr.2011.07.006

Ossewaarde, L., Hermans, E. J., van Wingen, G. A., Kooijman, S. C., Johansson, I. M., Bäckström, T., \& Fernández, G. (2010). Neural Mechanisms Underlying Changes in Stress-Sensitivity across the Menstrual Cycle. Psychoneuroendocrinology, 35, 47-55. https://doi.org/10.1016/j.psyneuen.2009.08.011

Ossewaarde, L., van Wingen, G. A., Rijpkema, M., Bäckström, T., Hermans, E. J., \& Fernández, G. (2013). Menstrual Cycle-Related Changes in Amygdala Morphology Are Associated with Changes in Stress Sensitivity. Human Brain Mapping, 34, 1187-1193. https://doi.org/10.1002/hbm.21502 
Ostlund, H., Keller, E., \& Hurd, Y. L. (2003). Estrogen Receptor Gene Expression in Relation to Neuropsychiatric Disorders. Annals New York Academic Science, 1007, 54-63. https://doi.org/10.1196/annals.1286.006

Pfaff, D. W., Vasudevan, N., Kia, H. K., Zhu, Y. S., Chan, J., Garey, J., Morgan, M., \& Ogawa, S. (2000). Estrogens, Brain and Behavior: Studies in Fundamental Neurobiology and Observations Related to Women's Health. Journal Steroid Biochemistry and Molecular Biology, 74, 365-373. https://doi.org/10.1016/S0960-0760(00)00114-X

Putman, P. (2011). Resting State EEG Delta-Beta Coherence in Relation to Anxiety, Behavioral Inhibition, and Selective Attentional Processing of Threatening Stimuli. International Journal Psychophysiology, 80, 63-68. https://doi.org/10.1016/j.ijpsycho.2011.01.011

Redei, E., \& Freeman, E. W. (1995). Daily Plasma Estradiol and Progesterone Levels over the Menstrual Cycle and Their Relation to Premenstrual Symptoms. Psychoneuroendocrinology, 20, 259-267. https://doi.org/10.1016/0306-4530(94)00057-H

Reed, S. C., Levin, F. R., \& Evans, S. M. (2008). Changes in Mood, Cognitive Performance and Appetite in the Late Luteal and Follicular Phases of the Menstrual Cycle in Women with and without PMDD (Premenstrual Dysphoric Disorder). Hormonal Behavioral, 54, 185-193. https://doi.org/10.1016/j.yhbeh.2008.02.018

Romans, S., Clarkson, R., Einstein, G., Petrovic, M., \& Stewart, D. (2012). Mood and the Menstrual Cycle: A Review of Prospective Data Studies. Gender Medicine, 9, 361-384. https://doi.org/10.1016/j.genm.2012.07.003

Roy, E., Montrsor, S., Abraham, P., \& Saumet, J. L. (1999). Spectrogram Analysis of Arterial Doppler Signals for On-Line Automated Hits Detection. Ultrasound Medicine Biology, 25, 349-359. https://doi.org/10.1016/S0301-5629(98)00173-2

Schmidt, P. J., Purdy, R. H., Moore, P. H., Jr. Paul, S. M., \& Rubinow, D. R. (1994). Circulating Levels of Anxiolytic Steroids in the Luteal Phase in Women with Premenstrual Syndrome and in Control Subjects. Journal Clinical Endocrinology Metabolism, 79, 1256-1260. https://doi.org/10.1210/jcem.79.5.7962316

Sigmon, S. T., Whitcomb-Smith, S. R., Rohan, K. J., \& Kendrew, J. J. (2004). The Role of Anxiety Level, Coping Styles, and Cycle Phase in Menstrual Distress. Journal Anxiety Disorder, 18, 177-191. https://doi.org/10.1016/S0887-6185(02)00243-8

Solís-Ortiz, S., \& Corsi-Cabrera, M. (2002). EEG Pattern of Anxiety along the Menstrual Cycle. Revista Mexicana Psicología, 19, 187-195.

Solís-Ortiz, S., Campos, R. G., Felix, J., \& Obregón, O. (2009). Coincident Frequencies and Relative Phases among Brain Activity and Hormonal Signals. Behavioral Brain Function, 5, 18. https://doi.org/10.1186/1744-9081-5-18

Solís-Ortiz, S., Guevara, M. A., \& Corsi-Cabrera, M. (2004). Performance in a Test Demanding Prefrontal Functions Is Favored by Early Luteal Phase Progesterone: An Electroencephalographic Study. Psychoneuroendocrinology, 29, 1047-1057. https://doi.org/10.1016/j.psyneuen.2003.10.007

Solís-Ortiz, S., Pérez-Luque, E., \& Gutiérrez-Muñoz, M. (2012). EEG Oscillations at Rest and during Performance of a Prefrontal Task Associated with the COMT Gene Polymorphism in Healthy Postmenopausal Women. In A. Costa, \& E. Villalba (Eds.), Horizons in Neuroscience Research (pp. 147-167). Hauppauge, NY: Nova Science Publishers Inc.

Solís-Ortiz, S., Pérez-Luque, E., \& Pacheco-Zavala, P. (2012). Resting EEG Activity and Ovarian Hormones as Predictors of Depressive Symptoms in Postmenopausal Women without a Diagnosis of Major Depression. Psychology, 3, 834-840.

https://doi.org/10.4236/psych.2012.329126 
Solís-Ortiz, S., Ramos, J., Arce, C., Guevara, M. A., \& Corsi-Cabrera, M. (1994). EEG Oscillations during Menstrual Cycle. International Journal Neuroscience, 76, 279-292. https://doi.org/10.3109/00207459408986010

Speilberg, C. D., Gorsush, R. L., \& Lushene, R. E. (1970). The State-Trait Anxiety Inventory Manual (STAI). Palo Alto: Consulting Psychologists Press.

Speilberg, C. D., Martínez-Urrutia, A., González-Reigosa, F., Nalacio, L., \& Díaz-Guerrero, R. (1980). Inventario de Autoevaluación (IDARE). México: El Manual Moderno.

Steriade, M. (2004). Cellular Substrates of Brain Rhythms. In E. Niedermeyer, \& F. H. Lopes Da Silva (Eds.), Electroencephalography: Basic Principles, Clinical Applications, and Related Fields (pp. 27-62). Baltimore, MD: Williams \& Wilkins.

Sussillo, D., Kundaje, A., \& Anastassiou, D. (2004). Spectrogram Analysis of Genomes, EURASIP. Journal Apply Signal Processing, 1, 29-42. https://doi.org/10.1155/S1110865704310048

Ter Horst, G. J. (2010). Estrogen in the Limbic System. Vitamin Hormone, 82, 319-338. https://doi.org/10.1016/S0083-6729(10)82017-5

Toffoletto, S., Lanzenberger, R., Gingnell, M., Sundstrom-Poromaa, I., \& Comasco, E. (2014). Emotional and Cognitive Functional Imaging of Estrogen and Progesterone Effects in the Female Human Brain: A Systematic Review. Psychoneuroendocrinology, 50, 28-52. https://doi.org/10.1016/j.psyneuen.2014.07.025

Tumyalis, A. V., \& Aftanas, L. I. (2014). Contribution of Neurophysiological Endophenotype, Individual Frequency of EEG Alpha Oscillations to Mechanisms of Emotional Reactivity. Bulletin Experimental Biology Medicine, 156, 711-716.

https://doi.org/10.1007/s10517-014-2431-2

van Broekhoven, F., Bäckström, T., van Luijtelaar, G., Buitelaar, J. K., Smits, P., \& Verkes, R. J. (2007). Effects of Allopregnanolone on Sedation in Men, and in Women on Oral Contraceptives. Psychoneuroendocrinology, 32, 555-564. https://doi.org/10.1016/j.psyneuen.2007.03.009

van Wingen, G. A., Ossewaarde, L., Bäckström, T., Hermans, E. J., \& Fernández, G. (2011). Gonadal Hormone Regulation of the Emotion Circuitry in Humans. Neuroscience, 191, 38-45. https://doi.org/10.1016/j.neuroscience.2011.04.042

van Wingen, G. A., van Broekhoven, F., Verkes, R. J., Petersson, K. M., Bäckström, T., Buitelaar, J. K., \& Fernández, G. (2008). Progesterone Selectively Increases Amygdala Reactivity in Women. Molecular Psychiatry, 13, 325-333.

https://doi.org/10.1038/sj.mp.4002030

Vasil'eva, V. V. (2005). Spectral and Coherent Characteristics of EEG in Women during Various Phases of Menstrual Cycle. Bulletin Experimental Biology Medicine, 140, 383-384. https://doi.org/10.1007/s10517-005-0496-7

Wang, M. (2011). Neurosteroids and GABA-A Receptor Functions. Frontiers Endocrinology, 2, 44. https://doi.org/10.3389/fendo.2011.00044

Weis, S., Hausmann, M., Stoffers, B., Vohn, R., Kellermann, T., \& Sturm, W. (2008). Estradiol Modulates Functional Brain Organization during the Menstrual Cycle: An Analysis of Interhemispheric Inhibition. Journal Neuroscience, 28, 13401-13410. https://doi.org/10.1523/JNEUROSCI.4392-08.2008

Wise, P. M. (2002). Estrogens and Neuroprotection. Trends in Endocrinology and Metabolism, 13, 229-230. https://doi.org/10.1016/S1043-2760(02)00611-2

Wollemann, M., \& Olaszy, G. (1977). Spectrogram Analysis of Different Alarm Calls in Gulls and Waders. Agressology, 18, 97-102. 
Woods, N. F., Lentz, M. J., Mitchell, E. S., Heitkemper, M., Shaver, J., \& Henker, R. (1998). Perceived Stress, Physiologic Stress Arousal, and Premenstrual Symptoms: Group Differences and Intra-Individual Patterns. Research Nursing Health, 21, 511-523.

https://doi.org/10.1002/(SICI)1098-240X(199812)21:6<511::AID-NUR5>3.0.CO;2-W 